\title{
Positive RT-PCR detected in patients recovered from COVID-19
}

\begin{abstract}
Dear Editor,
Positive real-time reverse transcription-polymerase chain reaction (RT-PCR) for SARS-CoV-2 nucleic acid following 2 consecutive negative RT-PCR tests have been reported in China ${ }^{1,2}$ and Korea. ${ }^{3}$ This has led to speculation regarding "persistent carrier states", "re-infections" or "re-activations" and raises questions about using negative RT-PCR as part of de-isolation criteria. We report a series of 5 such patients in Singapore with confirmed COVID-19 caused by SARS-CoV-2, and evaluated them further with viral culture and serological analysis. We include a discussion on the clinical implications.
\end{abstract}

All 5 patients had confirmed COVID-19 by positive RT-PCR tests from respiratory tract samples. Nasopharyngeal swabs were collected using a flexible minitip flocked swab (220252, Copan Diagnostics, Brescia, Italy), inserted half the distance from the nares to the base of the ear, or to a depth of approximately $5 \mathrm{~cm}$, done bilaterally. The laboratory used the NucliSens EasyMAG (BioMérieux, Marcy-l'Étoile, France) instrument to extract viral nucleic acids, with an input of $500 \mu \mathrm{L}$ and an elution volume of $55 \mu \mathrm{L}$, and the Agency for Science, Technology and Research (A*STAR) Fortitude Kit (Accelerate Technologies, Singapore) to test for SARS-CoV-2, both according to the manufacturers' instructions.

The clinical features of each case are shown in Table 1. The patients' ages range from 23 to 44 . Four patients had mild upper respiratory tract illness and one had radiographic evidence of pneumonia requiring supplemental oxygen during initial hospitalisation and received treatment with lopinavir-ritonavir. All 5 patients were immunocompetent and had no history of steroid use, use of traditional medicine or immunomodulating treatment. All patients clinically recovered from the acute illness and were discharged from either the acute hospital or a community isolation facility, after negative RT-PCR tests were performed on nasopharyngeal swabs twice, 24 hours apart. The mean duration from onset of illness to discharge was 21 days (range 18-23 days).

The patients subsequently sought medical attention post-discharge after an average of 9.6 days (range 1-24 days) with mild symptoms unrelated to COVID-19 or post-infectious cough, and had RT-PCR tests performed on nasopharyngeal swabs repeated, which returned positive. Notably for 4 of the patients, repeat testing was performed using the same A*STAR Fortitude Kit assay as described earlier. In Patient 4, the Cobas 6800/8800 (Roche Molecular Systems, Branchburg, US) test was used, which returned as a presumptive positive, being positive for the $\mathrm{E}$ gene target and negative for ORF$1 \mathrm{a} / \mathrm{b}$ gene target. All patients were then re-admitted for isolation as a precautionary measure. A repeat chest radiograph was performed for all patients, which were unremarkable. The previously noted pulmonary infiltrates for Patient 4 had completely resolved at the time of second presentation.

All repeat positive RT-PCR tests had cycle-threshold (Ct) values above 30. All patients had repeat nasopharyngeal swabs performed on day of re-admission and once every few days until their tests returned negative. The mean duration between the repeated positive RT-PCR result and subsequent negative RT-PCR result was 4.8 days (range 1-10). Viral culture was performed for all patients at the point of repeated positive RT-PCR. Isolation of SARS-CoV-2 viruses was attempted in African green monkey kidney cells (Vero E6; ATCC CRL-1586), which were cultured in Dulbecco's Modified Eagle's Medium (Sigma-Aldrich Corp., Germany) with 10\% heat-inactivated fetal calf serum and buffered with $2 \mathrm{~g}$ of sodium hydrogen carbonate. Nasopharyngeal swab specimens were resuspended in $3 \mathrm{ml}$ of Universal Transport Medium (Copan Diagnostics Inc., US) and stored at $-80^{\circ} \mathrm{C}$ before use. For all samples, $600 \mu \mathrm{L}$ was passed through $0.22 \mu \mathrm{m}$-pore-size Spin-X centrifuge tube filter (Corning, US), inoculated in VeroE6 cells and incubated at $37^{\circ} \mathrm{C}$. They were observed daily for evidence of cytopathic effect (CPE) and a further subculture onto fresh VeroE6 cells was performed after 7 days. After another 7 days of incubation, with no evidence of CPE, negative culture results were verified by specific RT-PCR targeting $\mathrm{E}$ and $\mathrm{N}$ genes. ${ }^{4}$ Virus culture was performed in a biosafety level 3 (BSL-3) laboratory. No viral growth was noted after two serial passages.

Serologic testing for receptor-binding domain (RBD) targeting neutralising antibodies for all patients were positive at the time of repeated positive RT-PCR tests, indicating an antibody response and inferred immunity to COVID-19. A SARS-CoV-2 surrogate virus neutralisation 


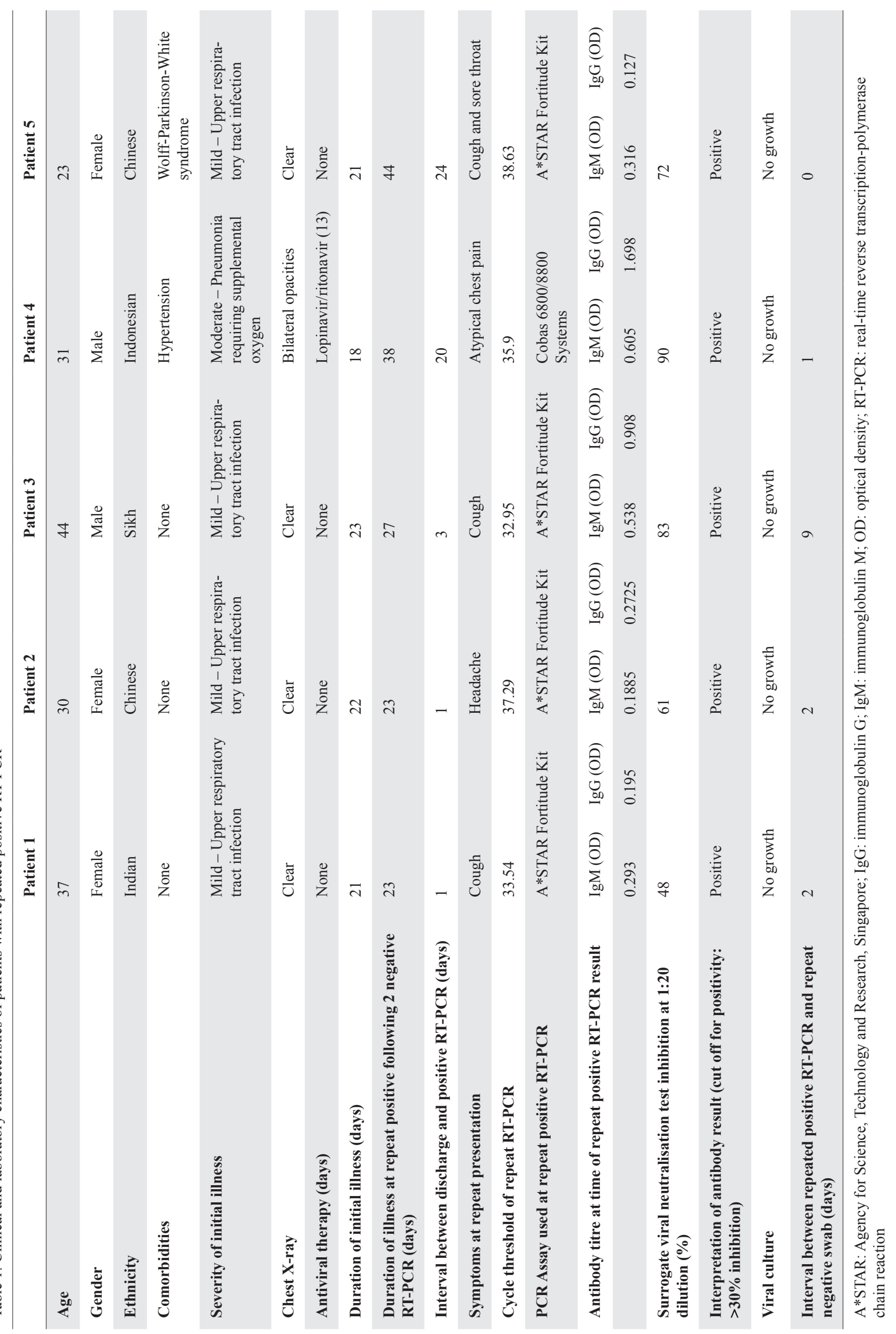


test based on antibody-mediated blockage of ACE2spike (RBD) protein-protein interaction was performed using methodology as described by Tan et al..$^{5} \mathrm{~A}$ binding enzyme-linked immunosorbent assay was also performed in capture format for the detection of immunoglobulin $\mathrm{M}$ and indirect format for the detection of immunoglobulin $\mathrm{G}$ antibodies against $\mathrm{RBD}$ protein in patient sera using a method described by Chia et al. ${ }^{6}$

No secondary transmission from time of discharge to re-admission was noted in these 5 patients and they were all discharged well after the second presentation.

A separate analysis of a cohort of 73 patients admitted to the National Centre for Infectious Diseases, Singapore demonstrated that SARS-CoV-2 could not be cultured when the $\mathrm{Ct}$ value was $\geq 30$, or after day 11 of illness. ${ }^{7}$ Since the initial 5 patients, we further evaluated 30 similar cases for possible COVID-19 re-infection. The mean duration from initial infection to suspected re-infection was 113 days (range 86-135), and all Ct values of repeat positive RT-PCR were above 35 . The high $\mathrm{Ct}$ values in our patients who had repeated positive RT-PCR with a mean of 34.7 (range 32.95-37.29) and transient re-positivity are reassuring for non-viable virus. Unfortunately for our initial 5 cases, we were unable to sequence the detected virus from both episodes to compare for phylogenetic similarity. In February 2021, the Ministry of Health, Singapore confirmed the first case of likely COVID-19 reinfection in Singapore. ${ }^{8}$ In addition to a repeat positive RT-PCR result, the patient was symptomatic and had a rise in neutralising antibodies compared to the period prior to the likely reinfection, suggesting exposure to a new infection.

The RT-PCR test may detect fragments of viral ribonucleic acid (RNA) in respiratory mucosal cells lining that shed intermittently over weeks or months. This could explain the "flip-flop" nature of RT-PCR testing from respiratory samples. We acknowledge that there may also be slight variation in various laboratory test methods and kits, as well as time or site of sampling, or degradation of viral RNA during transport and storage which may give rise to false negative results. ${ }^{9}$

Based on the high $\mathrm{Ct}$ values from repeated positive RT-PCR tests, negative viral cultures and presence of antibodies in these 5 patients, we surmise that the repeated positive RT-PCR samples likely contained non-viable virus, and that the patients were non-infectious. Our findings are consistent with those of the Korea Centers for Disease Control and Prevention, where patients who recovered from COVID-19 may continue to have detectable viral nucleic acid though not equated with infectivity or viable virus. ${ }^{10}$ Currently transmission-based precautions for patients with COVID-19 have been recommended to be discontinued after 20-21 days from onset of illness ${ }^{7,11}$ and if patients have clinically recovered. The World Health Organization recommends at least 10 days from symptom onset (or test-positivity) with at least 3 additional days without symptoms (for symptomatic cases) before de-isolation, and microbiological testing (2 sequential negative RT-PCR tests, 24 hours apart), which may also be considered as part of discharge criteria. ${ }^{12}$ Our data are in-line with these recommendations, and indicate that while recovered patients may continue to shed viral fragments in the immediate post-recovery period, they do not pose a significant public health risk to the community. They may be safely discharged after 2 sequential negative RT-PCR test results if they have clinically recovered, or after the requisite period of isolation for time-based de-isolation strategies. Prolonged and intermittent detection of SARS-CoV-2 viral RNA in respiratory specimens may occur, and there have been a few documented true cases of COVID-19 re-infection. ${ }^{13}$ While the majority of cases to date seems to reflect non-viable viral RNA, true COVID-19 reinfection is possible but seems relatively uncommon, in comparison to the total global case counts.

Certainly, with the emergence of variants of concern, and waning immunity after natural infection or vaccination, this is a phenomenon which needs to be paid attention to. Careful clinical interpretation of $\mathrm{Ct}$ values and further testing with viral culture, genetic sequencing and quantitative evaluation of neutralising antibody titres are necessary to distinguish these.

\section{Acknowledgements}

The serology work in this study was funded by grants (STPRG-FY19-001 and COVID19RF-003) from the National Medical Research Council, Singapore. The authors would like to acknowledge the National University of Singapore BSL3 facility for technical assistance.

\section{REFERENCES}

1. Lan $\mathrm{L}, \mathrm{Xu}$ D, Ye G, et al. Positive RT-PCR test results in patients recovered from COVID-19. JAMA 2020;323:1502-3.

2. Yuan J, Kou S, Liang Y, et al. PCR assays turned positive in 25 discharged COVID-19 patients. Clin Infect Dis 2020:ciaa398.

3. Reuters. South Korea reports recovered coronavirus patients testing positive again, 10 April 2020. Available at: https://www. reuters.com/article/us-health-coronavirus-southkorea/south-koreareports-recovered-coronavirus-patients-testing-positive-againidUSKCN21S15X. Accessed on 24 September 2020.

4. Corman VM, Landt O, Kaiser M, et al. Detection of 2019 novel coronavirus (2019-nCoV) by real-time RT-PCR. Euro Surveill 2020;25:2000045. 
5. Tan CW, Chia WN, Qin X, et al. A SARS-CoV-2 surrogate virus neutralization test based on antibody-mediated blockage of ACE2-spike protein-protein interaction. Nat Biotechnol 2020;38:1073-8.

6. Chia WN, Tan CW, Foo R, et al. Serological differentiation between COVID-19 and SARS infections. Emerg Microbes Infect 2020; 9:1497-1505.

7. National Centre for Infectious Diseases and Chapter of Infectious Disease Physicians, Academy Medicine of Singapore. Period of infectivity to inform strategies for de-isolation for COVID-19 patients, 23 May 2020. Available at: https://www.ncid.sg/Documents/ Period\%20of\%20Infectivity\%20Position\%20Statementv2.pdf. Accessed on 23 May 2020.

8. The Straits Times. First case of likely Covid-19 reinfection in Singapore detected, located in dormitory. 6 February 2021. Available at: https://www.straitstimes.com/singapore/health/first-case-of-likelycovid-19-reinfection-in-singapore-located-in-dormitory. Accessed on 6 February 2021.

૫. Koh D, Cunningham AC. Counting coronavirus disease 2019 (COVID-19) cases: case definitions, screened populations and testing techniques matter. Ann Acad Med Singap 2020;49:161-5.

प७. The Korea Herald. Tests in recovered patients found false positives, not reinfections, experts say, 29 April 2020. Available at: http://m.koreaherald.com/view.php?ud=20200429000724. Accessed on 24 September 2020.

11. United States Centers for Disease Control and Prevention. Discontinuation of transmission-based precautions and disposition of patients with COVID-19 in healthcare settings (Interim guidance), 10 August 2020. Available at: https://www.cdc.gov/coronavirus/2019ncov/hcp/disposition-hospitalized-patients.html. Accessed on 28 September 2020.
1]. World Health Organization. Criteria for releasing COVID-19 patients from isolation, 17 June 2020. Available at: https:/www.who.int/ publications/i/item/criteria-for-releasing-covid-19-patients-fromisolation. Accessed on 28 September 2020.

11. To KK, Hung IF, Ip JD, et al. COVID-19 re-infection by a phylogenetically distinct SARS-coronavirus-2 strain confirmed by whole genome sequencing. Clin Infect Dis 2020; ciaa1275.

Glorijoy Shi En Tan, ${ }^{1,2}{ }_{M R C P(U K)}$, Ying Ding, ${ }^{1}{ }_{P h D}$, Lin $\underline{\text { Cui }},{ }_{P h D}^{1}$, Tze-Minn $\underline{\text { Mak }},{ }^{1}{ }_{P h D}$, Chee Keng $\underline{\text { Mok }},{ }^{3}{ }_{P h D}$, Asok Kurup, ${ }^{4}{ }_{M R C P(U K)}$, Purnima Parthasarathy, ${ }^{5}{ }_{M P H}$, Wan-Ni Chia, ${ }^{6}{ }_{P h D}$, Lin-Fa Wang, ${ }^{6}{ }_{P h D}$, Raymond TP $\underline{\text { Lin }},{ }_{\text {FRCPA, }}^{1}$ Yee-Sin Leo, ${ }_{F R C P}$, Shawn $\underline{\text { Vasoo, }},{ }^{1,2}{ }_{M R C P}$

${ }^{1}$ National Centre for Infectious Diseases, Singapore

${ }^{2}$ Department of Infectious Diseases, Tan Tock Seng Hospital, Singapore

${ }^{3}$ Biosafety Level 3 Core Facility, Yong Loo Lin School of Medicine, National University of Singapore, Singapore

${ }^{4}$ Infectious Diseases Care Private Ltd, Mount Elizabeth Medical Centre, Singapore

${ }^{5}$ Khoo Teck Puat Hospital, Singapore

${ }^{6}$ Programme in Emerging Infectious Diseases, Duke-NUS Medical School, Singapore

Correspondence: Dr Glorijoy Shi En Tan, National Centre for Infectious Diseases, 16 Jalan Tan Tock Seng, Singapore 308442.

Email: glorijoy_se_tan@ttsh.com.sg 